\begin{tabular}{|c|c|c|} 
Dinamika Journal, Vol. 2 No. 1, 2020 \\
ISSN ONLINE : 2686-2158
\end{tabular}

\title{
PENINGKATAN NILAI TAMBAH CURUG BANDUNG, DESA SUMINGKIR, KECAMATAN KUTASARI, KABUPATEN PURBALINGGA SEBAGAI DESTINASI GEOWISATA BARU
}

\author{
FX Anjar Tri Laksono ${ }^{1 *}$, Purwanto Bekti Santoso ${ }^{2}$, Indra Permanajati ${ }^{1}$ \\ ${ }^{1}$ Teknik Geologi, Universitas Jenderal Soedirman, Indonesia \\ 2 Teknik Sipil, Universitas Jenderal Soedirman, Indonesia \\ *Corresponding author : anjar.trilaksono@unsoed.ac.id
}

Received 4 November 2019; Accepted 22 January 2020; Available online 26 February 2020

\begin{abstract}
Abstrak
Desa Sumingkir, Kecamatan Kutasari, Kabupaten Purbalingga memiliki potensi wisata alam yang menarik. Curug Bandung merupakan fenomena alam yang dapat berkembang menjadi destinasi geowisata baru bagi turis lokal. Sebelum dilakukan peningkatan nilai tambah, jumlah wisatawan yang mengunjungi Curug Bandung sangat sedikit. Hal ini terjadi karena obyek wisata tersebut belum tertata dengan baik. Oleh sebab itu, kegiatan ini bertujuan memberikan pendampingan kepada masyarakat desa melalui program peningkatan nilai tambah Curug Bandung sehingga menjadi tempat wisata yang ramai pengunjung. Dalam kegiatan tersebut, area sekitar Curug Bandung dibersihkan dari sampah plastik dan dibangun arena khusus untuk tempat pemancingan. Pembendungan dilakukan untuk mengurangi debit aliran air dari air terjun menuju sungai sehingga kedalaman kolam pemandian yang berada di bawah air terjun bertambah. Fasilitas penunjang seperti kedai kopi dan warung makan juga dibangun sebagai tempat istirahat dan bersantai para pengunjung setelah berendam di air terjun. Setiap pengunjung yang ingin memasuki tempat wisata membayar tiket masuk sebesar Rp 20.000 per orang. Pendapatan tersebut digunakan untuk pemeliharaan tempat wisata Curug Bandung. Komunitas sadar wisata dibentuk sebagai pihak yang bertanggungjawab terhadap pengelolaan Curug Bandung. Kesimpulan dari kegiatan ini adalah peningkatan nilai tambah Curug Bandung telah berhasil meningkatkan jumlah kunjungan wisatawan lokal dan menjadi sumber pendapatan baru untuk Desa Sumingkir.
\end{abstract}

Kata kunci : Curug Bandung, geowisata, Desa Sumingkir, Kecamatan Kutasari, Purbalingga.

\begin{abstract}
Sumingkir Village, Kutasari District, Purbalingga Regency has attractive natural tourism potential. Curug Bandung is a natural phenomenon that can develop to be a new geo-tourism destination for local tourists. Before the revitalization, the number of tourists that visited Curug Bandung was very slight. This happens because it has not been well ordered.
\end{abstract}


Therefore, this activity aims to assist village communities in the revitalization of Curug Bandung to be a tourist attraction that is full of visitors. In this activity, the area around Curug Bandung was cleaned of rubbish and provided a special place for fishing grounds. The dam was carried out to hold the water flow from the waterfall to the river so that the depth of the bathing pool under the waterfall increased. Supporting facilities such as coffee shops and food court are also built as a place to rest and relax the visitors after soaking in a waterfall. Every visitor who wants to visit a tourist attraction pays an entrance ticket for Rp. 20,000 each person. The income is used for the Curug Bandung conservation site. Tourism conscious community was formed as the party responsible for the management of Bandung Waterfall. The conclusion of this study is the revitalization of Curug Bandung has succeeded in increasing the number of local tourist visits and become a new income for the Sumingkir Village.

Keywords: Curug Bandung, geo-tourism, Sumingkir Village, Kutasari District, Purbalingga

\section{PENDAHULUAN}

Desa Sumingkir yang terletak di Kecamatan Kutasari, Kabupaten Purbalingga, Provinsi Jawa Tengah (gambar 1) memiliki potensi alam yang sangat menarik untuk dikunjungi dan dijelajahi. Salah satu potensi yang dapat dikembangkan menjadi destinasi wisata baru adalah Curug Bandung. Akan tetapi, kunjungan wisatawan ke tempat wisata tersebut masih sangat sedikit. Dalam wawancara dengan Kepala Desa Sumingkir tahun 2019, Tuting Haryati menyatakan: "Desa Sumingkir sangat membutuhkan inovasi untuk meningkatkan jumlah turis lokal ke Curug Bandung sehingga dapat menjadi sumber pendapatan desa dan meningkatkan kesejahteraan masyarakat lokal". Oleh karena itu, perangkat Desa Sumingkir mengajak perguruan tinggi untuk memberikan pendampingan dalam rencana pengembangan geowisata tersebut (Junaidi \& Paribrata, 2015).

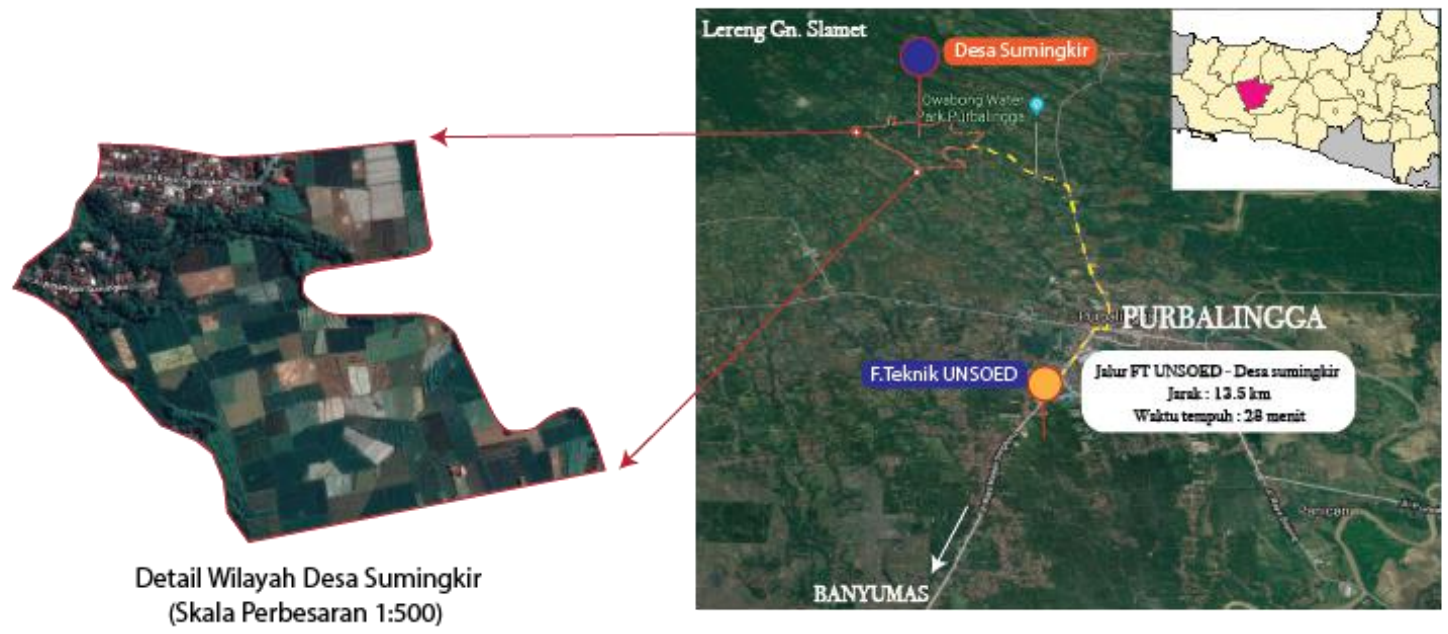

Gambar 1. Peta lokasi Desa Sumingkir, Kecamatan Kutasari, Kabupaten Purbalingga dan jaraknya terhadap kampus Fakultas Teknik, Universitas Jenderal Soedirman

Belum adanya komunitas yang mendorong dan memberikan inovasi kepada perangkat desa dalam melakukan revitalisasi objek wisata tersebut juga menjadi hambatan lain dalam meningkatkan jumlah kunjungan wisatawan (Syahyuti, 2006). Revitalisasi Curug Bandung sangat penting untuk dilakukan karena dapat menjadi destinasi geowisata baru di Kabupaten Purbalingga yang mempunyai multiply effect bagi perekonomian desa maupun kabupaten (Palupi et al., 2016). Ketika Curug Bandung menjadi objek wisata yang banyak dikunjungi 
orang, bisnis usaha mikro kecil dan menengah (UMKM) di Desa Sumingkir akan berkembang pesat dan tentunya pendapatan masyarakat juga meningkat. Hal tersebut sesuai pendapat Kazimoto, 2013 bahwa berkembangnya sektor usaha skala rumah tangga atau UMKM dapat meningkatkan pendapatan masyarakat dan memiliki dampak secara langsung terhadap kesejahteraan masyarakat.

Tujuan dari kegiatan ini adalah mendorong masyarakat Desa Sumingkir untuk melakukan revitalisasi geowisata Curug Bandung sehingga banyak dikunjungi oleh wisatawan lokal. Manfaat yang didapat oleh masyarakat setelah revitalisasi selesai adalah meningkatnya bisnis UMKM dan pendapatan masyarakat. Revitalisasi meliputi pembentukan komunitas masyarakat sadar wisata, pembersihan lokasi, penambahan fasilitas hiburan dan unsur penunjang seperti tempat memancing, kedai kopi, dan warung makan (Cathart \& Larry, 1974). Komunitas masyarakat sadar bencana diberikan kewenangan khusus untuk mengelola Curug Bandung namun tetap dalam pengawasan kepala desa. Tim pendamping bersama komunitas tersebut selaku mitra secara terus menerus melakukan inovasi agar wisatawan datang ke objek wisata tersebut.

\section{METODE PELAKSANAAN}

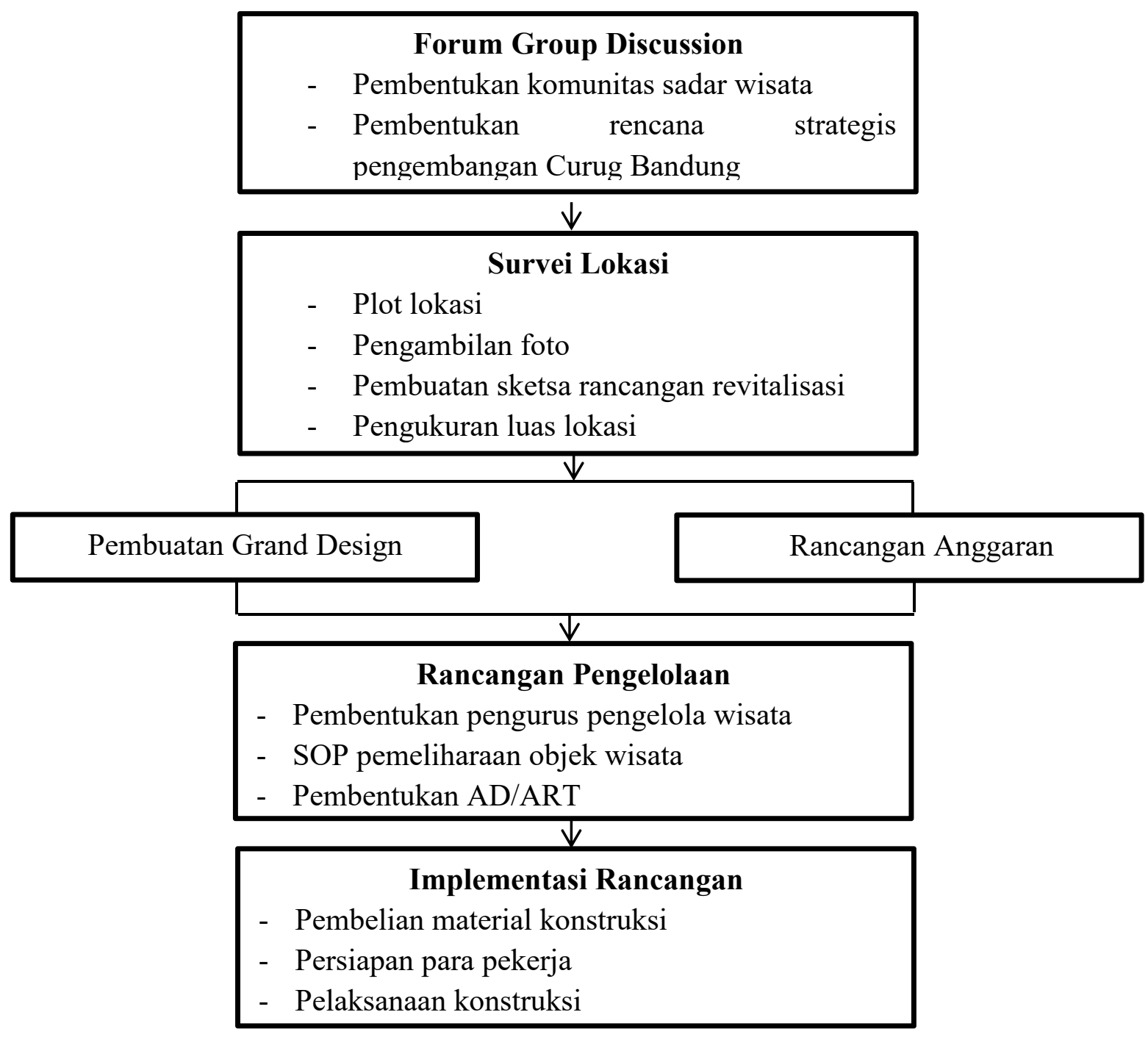

Gambar 2. Diagram Alir pelaksanaan kegiatan revitalisasi Curug Bandung 
Berdasarkan gambar 2 kegiatan revitalisasi Curug Bandung diawali dengan Forum Group Discussion (FGD) untuk mendengarkan berbagai masukkan mengenai konsep pengembangan Curug Bandung sebagai geowisata. Kegiatan ini melibatkan karang taruna, perangkat desa, kepala dusun, tokoh masyarakat, tokoh agama, dosen teknik geologi Universitas Jenderal Soedirman (UNSOED), dan dosen teknik sipil UNSOED. Sebanyak kurang lebih 100 orang hadir dan memberikan pendapat dalam membentuk komunitas sadar wisata Desa Sumingkir dan rencana strategis pengembangan Curug Bandung menjadi geowisata (gambar 3). Setelah ada berbagai kesepakatan, tahap selanjutnya adalah melakukan kunjungan lokasi Curug Bandung untuk mengambil beberapa foto air terjun, jalan menuju lokasi, dan sungai di sekitar lokasi. Hal tersebut diperlukan sebagai dasar dalam membuat design revitalisasi (Hadiwijoyo, 2012). Pada tahap ini juga dibuat sketsa kondisi tempat wisata dan sketsa rancangan revitalisasi sementara (Simanungkalit \& Sari, 2015). Pengukuran luas lokasi digunakan sebagai pedoman untuk membangun beberapa fasilitas publik yang dapat dimanfaatkan oleh wisatawan saat berkunjung ke objek wisata tersebut (Hikmat, 2004).
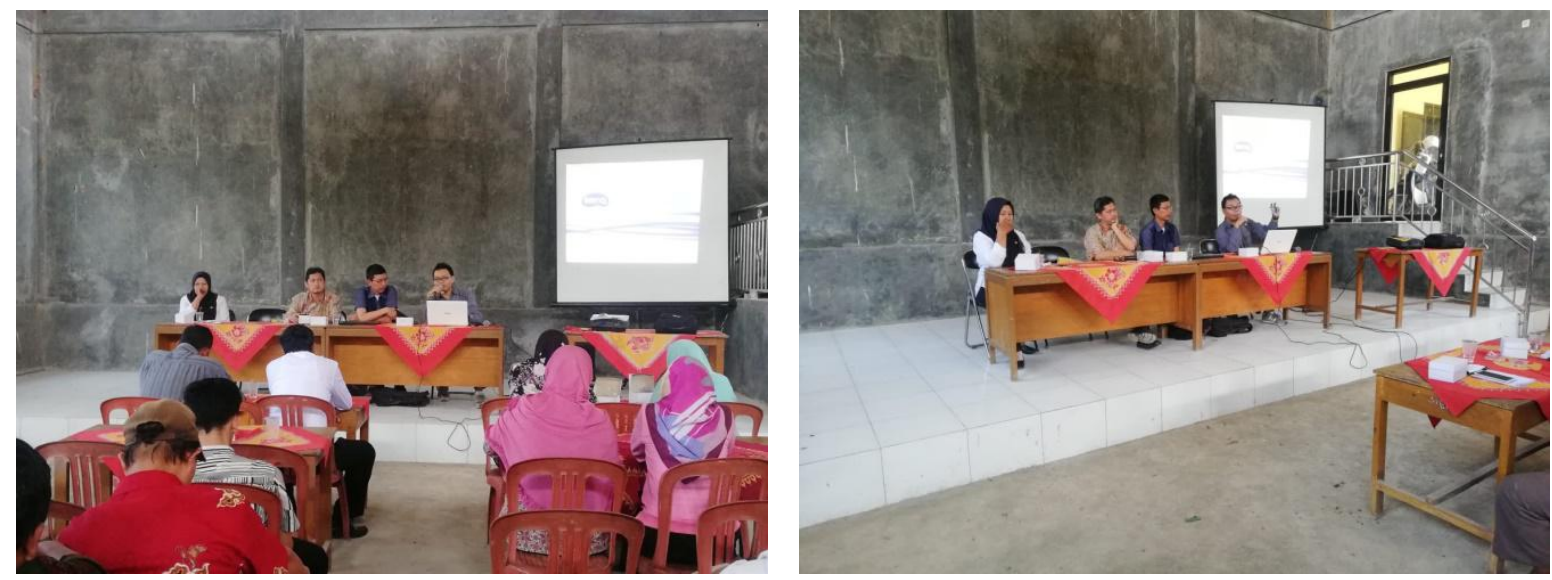

Gambar 3. Sosialisasi revitalisasi Curug Bandung melalui kegiatan FGD yang dihadiri oleh tokoh masyarakat, karang taruna, perangkat Desa Sumingkir, perwakilan dosen UNSOED.

Tahap berikutnya adalah pembuatan grand design yang mencakup penataan lokasi wisata, jalan menuju area wisata, fasilitas hiburan, dan event rutin di objek wisata tersebut yang dapat dimanfaatkan sebagai daya tarik serta ajang promosi (Sudana, 2013). Pembuatan rancangan anggaran disesuaikan dengan kebutuhan material untuk membangun fasilitas hiburan dan melakukan penataan lokasi termasuk jumlah pekerja yang diperlukan dalam pelaksanaan revitalisasi (Friedman, 1992) . Rancangan pengelolaan termasuk pembentukan pengurus pengelola wisata, standard operational procedure (SOP) pemeliharaan objek wisata, dan pembentukan anggaran dasar dan aturan rumah tangga (AD/ART) (Sumodiningrat, 1999) . Tahap implementasi rancangan meliputi pembelian material konstruksi, persiapan para pekerja, dan pelaksanaan konstruksi hingga revitalisasi selesai dilakukan (Cresswell, 2009).

\section{HASIL DAN PEMBAHASAN}

Hasil dari FGD yang melibatkan berbagai pihak seperti dosen teknik sipil dan geologi UNSOED, tokoh masyarakat, tokoh agama, Kepala Desa, Badan Permusyawaratan Desa (BPD), kepala dusun, kepala urusan pembangunan, Karang Taruna, Badan Usaha Milik Desa (BUMDES), dan para ketua RT/RW sepakat untuk membentuk komunitas sadar wisata Desa Sumingkir yang anggotanya terdiri dari beberapa perwakilan para peserta FGD tersebut. Komunitas sadar wisata kemudian membentuk rencana strategis pengembangan Curug Bandung sebagai destinasi baru geowisata Kabupaten Purbalingga. Air terjun merupakan 
nilai jual utama dari obyek wisata ini (gambar 4A). Selain itu terdapat kolam pemandian di bawah air terjun yang semuanya dapat diakses oleh para wisatawan. Pembendungan aliran air dari air terjun menuju Sungai Bandung dilakukan untuk memperdalam kolam pemandian (gambar 4B). Adanya penambahan kedalaman, para wisatawan dapat melakukan loncat indah dari atas air terjun ke kolam pemandian dengan aman. Sebanyak 7 lapak pedagang dibangun di sekitar area air terjun sebagai fasilitas bersantai untuk para wisatawan. Ketujuh lapak pedagang tersebut menyediakan berbagai kuliner khas Desa Sumingkir seperti kopi, pecel kangkung, mendoan, keripik talas, bakwan jagung, dan penyetan ikan dengan bumbu khas Desa Sumingkir.

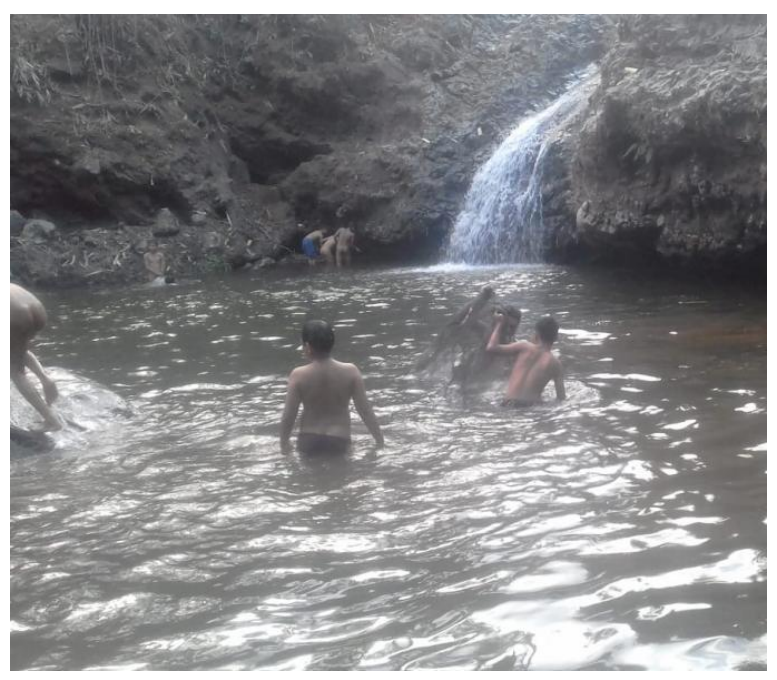

A

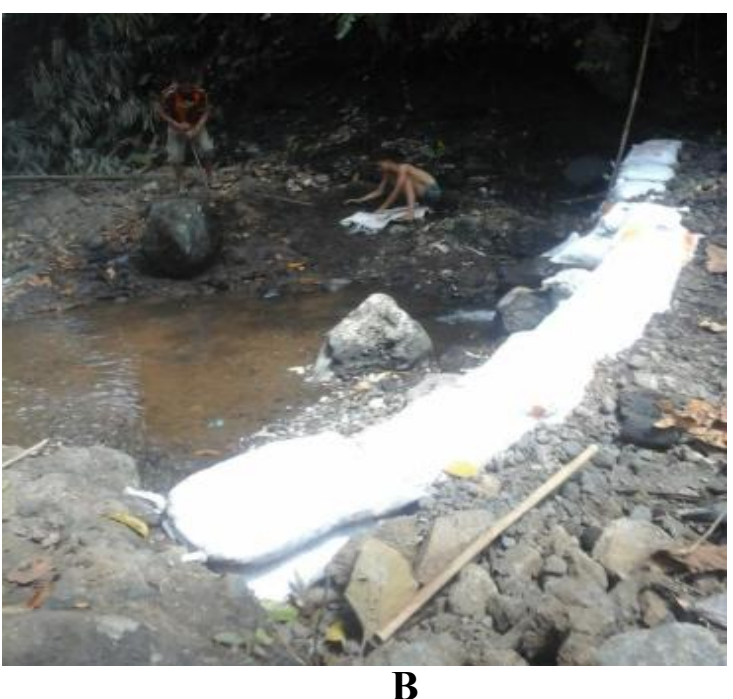

B

Gambar 4. A) air terjun Curug Bandung hasil rangkaian erosi formasi batuan dan aliran arus karena perbedaan elevasi. B) Pembendungan dengan menggunakan karung berisi pasir dan batu pada batas antara kolam bawah air terjun dan daerah aliran sungai.

Fasilitas hiburan juga disediakan di sekitar tempat wisata seperti panggung seni yang menampilkan organ tunggal dan tari-tarian dari para seniman Desa Sumingkir. Setiap hari Senin hingga Kamis dan hari Minggu jam 10.00-17.00 WIB diadakan lomba memancing yang dapat diikuti oleh semua pengunjung (gambar 5A). Slogan yang diusung pada lomba memancing ini adalah "mancing di sungai sensasi kolam ikan". Sungai Bandung memiliki banyak ikan dengan berbagai jenis seperti mujair, sepat, patin, bawal, gurame, nila, belut, dan mas. Hanya dengan tiket masuk sebesar Rp. 20.000/orang para peserta lomba dapat sepuasnya memancing selama 7 jam. Bagi para peserta yang merasa lelah bisa sesekali menikmati kuliner tradisional yang murah dan enak pada 7 lapak pedagang yang telah disediakan pengelola wisata (gambar 5B). Iringan musik dan tari-tarian akan menghibur para peserta dari jam 10.00 hingga jam 16.00 WIB. Sehingga para peserta lomba tidak merasa jenuh saat menunggu kailnya mendapatkan ikan. Saat ini ada tiga sponsor yang sudah masuk untuk mendukung agenda rutin memancing di Curug Bandung. Ketiga sponsor tersebut adalah XL, im3, dan Sampoerna. Perusahaan telekomunikasi XL memberikan bantuan tenda secara gratis kepada para pedagang yang membuka usahanya di area wisata tersebut. Pihak im3 berkontribusi menyediakan doorprize dengan berbagai hadiah yang menarik bagi para peserta lomba memancing. Perusahaan rokok sampoerna memberikan harga yang sangat murah untuk harga per bungkus rokok filter. Satu bungkus rokok dapat dibeli hanya dengan Rp. 10.000 . 


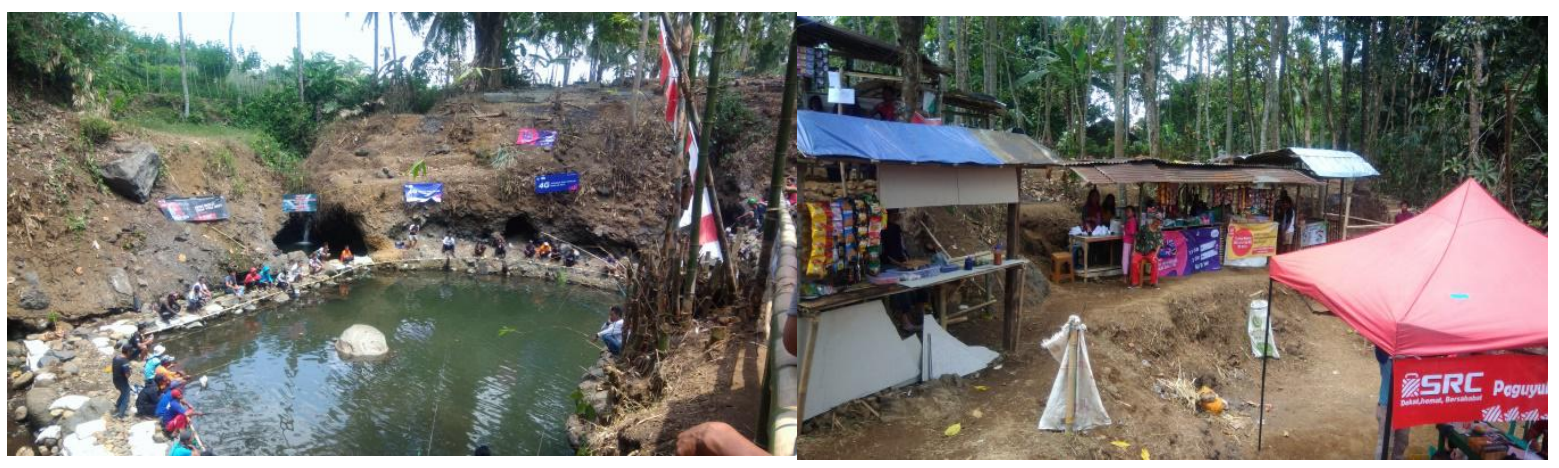

A

B

Gambar 5. A) Lomba memancing yang dilakukan setiap lima hari sekali dalam seminggu dan disponsori oleh beberapa perusahaan. B) Warung makan sebagai tempat istirahat sekaligus menikmati kuliner khas Desa Sumingkir dan Purbalingga.

Komunitas sadar wisata bekerjasama dengan Teknik Geologi, Universitas Jenderal Soedirman memiliki beberapa kerjasama. Wujud dari kerjasama itu adalah obyek wisata Curug Bandung dijadikan salah satu destinasi field trip mahasiswa Teknik Geologi UNSOED untuk mata kuliah geowisata, hidrogeologi, geologi dasar, vulkanologi, dan petrologi. Selama program ini berjalan, telah banyak kegiatan field trip yang dilakukan oleh para mahasiswa geologi (gambar 6 A dan B). Bahkan, beberapa kali mahasiswa geologi dari kampus lain seperti UGM, ITB, dan UNPAD melakukan kegiatan ekskursi lapangan di obyek wisata ini. Dalam waktu yang singkat, Curug Bandung juga menjadi destinasi wisata edukasi. Papan informasi mengenai proses terbentuknya air terjun, sejarah terbentuknya lava, struktur geologi, dan jenis litologi dipasang di area utama wisata yang berdekatan dengan air terjun agar masyarakat awam dapat belajar ilmu geologi dengan menyenangkan. Beberapa anggota komunitas sadar wisata juga bersedia menjadi tour guide untuk menjelaskan fenomenafenomena geologi yang dapat dipelajari dari Curug Bandung.
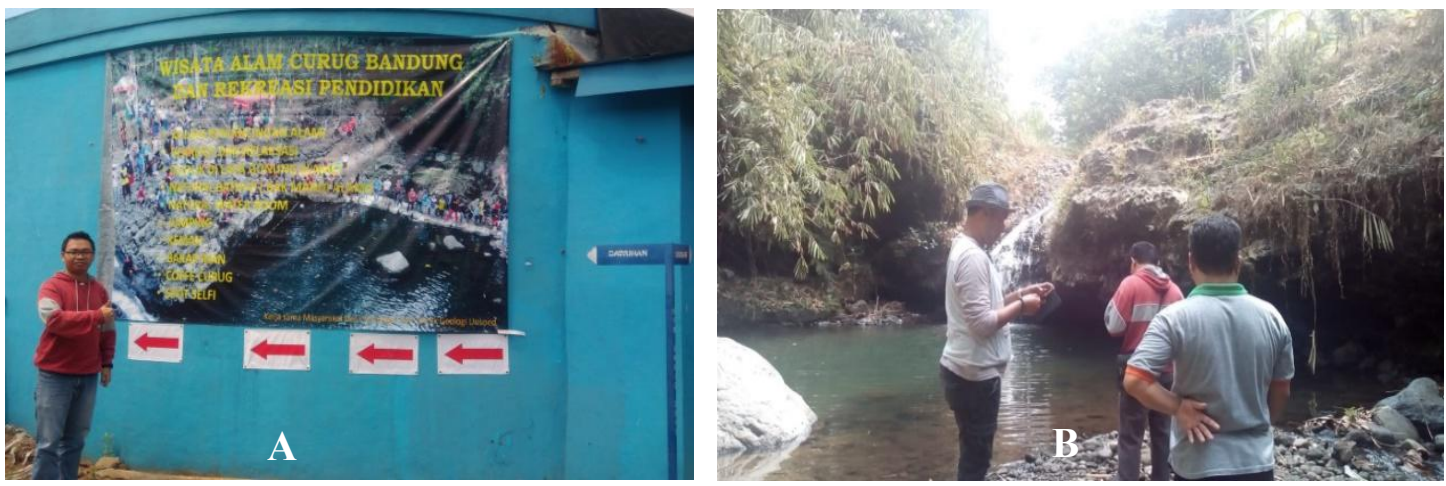

Gambar 6. A) Poster promosi geowisata Curug Bandung yang juga menampilkan kerjasama antara Teknik Geologi UNSOED dengan Desa Sumingkir. B) Kegiatan lapangan dan penjelasan sejarah geologi Curug Bandung oleh Fadlin, S.T., M.Eng selaku dosen Teknik Geologi UNSOED.

Jumlah wisatawan yang berkunjung ke Curug Bandung setelah dilakukan revitalisasi mengalami kenaikan hampir 10 kali lipat. Sebelum dilakukan revitalisasi, kunjungan wisatawan per hari hanya 8-10 orang, tetapi setelah dilakukan revitalisasi jumlah kunjungan meningkat menjadi berkisar antara $80-85$ orang. Hal ini menunjukkan bahwa program revitalisasi berjalan sesuai harapan. Jumlah kunjungan juga menunjukkan kecenderungan yang meningkat. Pada awal-awal pasca revitalisasi peningkatan hanya berkisar antara 2-3 kali 
lipat. Tetapi setelah berjalannya waktu, jumlah kunjungan meningkat menjadi kurang lebih 10 kali lipat dan ini hanya berselang dua minggu pasca revitalisasi. Pendapatan rata-rata masyarakat Desa Sumingkir juga mengalami kenaikan yang cukup signifikan dari hanya Rp. 1.500.000/bulan menjadi Rp. 2.000.000/bulan. Berkembangnya sektor perdagangan terutama bisnis kuliner dan kerajinan tangan menjadi faktor pendorong terkuat peningkatan pendapatan masyarakat. Konsep geowisata yang merupakan gabungan antara fungsi edukasi dan rekreasi ternyata mampu meningkatkan jumlah kunjungan wisatawan lebih banyak dibandingkan dengan hanya menonjolkan fungsi rekreasinya saja.

\section{KESIMPULAN}

Program revitalisasi Curug Bandung berhasil meningkatkan jumlah wisatawan hingga 10 kali lipat jika dibandingkan sebelum revitalisasi. Hal tersebut juga diikuti dengan meningkatknya pendapatan masyarakat Desa Sumingkir karena banyaknya wisatawan yang datang memiliki efek positif terhadap berkembangnya aktivitas perdagangan terutama bisnis kuliner dan kerajinan tangan. Hasil penjualan tiket masuk lokasi wisata juga dapat digunakan untuk melakukan pemeliharaan dan pengelolaan Curug Bandung sehingga jumlah kunjungan wisatawan tetap berada pada kecenderungan yang positif. Program-program selanjutnya yang dapat dilakukan berkenaan dengan mewujudkan Desa Sumingkir sebagai tujuan wisata populer di Kabupaten Purbalingga adalah dengan melakukan beberapa revitalisasi obyekobyek potensi wisata yang lain seperti mata air Kali Sirah, mata air Karang Pelus, bukit Lemmah Metteng, dan makam Kyai Jeneng.

\section{UCAPAN TERIMA KASIH}

Kegiatan revitalisasi Curug Bandung sebagai destinasi geowisata baru di Kabupaten Purbalingga adalah hasil kerjasama antara Karang Taruna yang juga sebagai kelompok sadar wisata, akademisi Universitas Jenderal Soedirman, tokoh masyarakat, dan perangkat Desa Sumingkir yang meliputi kepala desa, BPD, BUMDES, kepala urusan pembangunan, dan kepala dusun. Dana awal revitalisasi bersumber dari iuran sukarela warga Desa Sumingkir yang kemudian pada tahapan selanjutnya mendapatkan pendanaan dari dana desa yang nilai totalnya mencapai Rp. 500 juta. Ucapan terima kasih kepada beberapa perusahaan telekomunikasi seperti XL dan im3 serta perusahaan rokok sampoerna yang telah berkontribusi menjadi sponsor khususnya dalam mendukung ajang lomba memancing dan penyediaan lapak pedagang di sekitar area wisata.

\section{DAFTAR PUSTAKA}

Cathart, R., Larry, A. 1974. Small Group Communication. Brown Company, New York. 432 pp.

Cresswell, J. 2009. Qualitative, Quantitative, and Mixed Methods Approaches. SAGE Publications, California. 295 pp.

Friedman, J. 1992. Empowerment The Politics of Alternative Development. Blackwell Publishers, Cambridge. 212 pp.

Hadiwijoyo, S. 2012. Perencanaan Pariwisata Perdesaan Berbasis Masyarakat (Sebuah Pendekatan Konsep). Graha Ilmu, Yogyakarta. 111 pp.

Hikmat, H. 2004. Strategi Pemberdayaan Masyarakat. Bandung, Humoniora. 196 pp.

Junaidi, M., \& Paribrata, A. 2015. Pedoman Standar Layanan Informasi Publik untuk Pemerintahan Desa. Komisi Informasi Provinsi Jawa Timur, Surabaya. 70 pp. 
Kazimoto, P. 2013. The Effect of Village Development Strategies on Community Socio Economic Development in Tanzania, Arumeru District. International Journal of Research in Social Sciences 3, 33-39.

Palupi, S., Ulfiah, U., Prasetyohadi, Yulia, S., Sabik, A. 2016. Buku Panduan Pelaksanaan Undang-Undang Desa Berbasis Hak. Lakpesdam PBNU, Jakarta. 172 pp.

Simanungkalit, V., Sari, D. 2015. Buku Panduan Pengembangan Desa Wisata Hijau. Kementerian Koperasi dan UKM Republik Indonesia, Jakarta. 70 pp.

Sudana, I. 2013. Stategi Pengembangan Desa Wisata Ekologis di Desa Belimbing, Kecamatan Pupuan, Kabupaten Tabanan. Analisis Pariwisata 13, 11-31.

Sumodiningrat, G. 1999. Pemberdayaan Masyarakat dan Jaring Pengaman Sosial. Gramedia Pustaka Utama, Jakarta. 334 pp.

Syahyuti. 2006. Konsep Penting dalam Pembangunan Pedesaan dan Pertanian. Bina Rena Pariwara, Jakarta. 262 pp. 